\title{
In dialogue with nature: Experiential learning through farming in a university common core science general ed- ucation course
}

\author{
Ming Li * \\ The Chinese University of Hong Kong, Shatin, Hong Kong
}

\author{
Keywords \\ GE \\ Experiential learning \\ Farming \\ Agriculture \\ In dialogue with nature
}

Received: 13 August 2018

Accepted: 6 November 2018

Published: 1 October 2018

\begin{abstract}
The objective of this study is to investigate the effects of experiential learning through farming on students' learning in the common core science GE course. A total of 101 year-one and year-two university students from different disciplines had joined the farming practicum, in which hands-on farm work and guided discussion were included. Quantitative surveys and qualitative feedback revealed that the farming practicum helped students understand the course materials better, foster their reflection on the environmental, social and political issues, and gain the knowledge and techniques in farming. This study provides insightful findings to support the implementation of experiential learning through farming in the university science GE course. Given the diverse aspects and interdisciplinary nature of agriculture, experiential learning through farming can be extended to other GE courses, including the humanity courses, to inspire the students and cultivate them into better global citizens.
\end{abstract}

(C) 2018 The Author(s). Published by TAF Publishing.

\section{INTRODUCTION}

GE embraces the development of a broad intellectual perspective through the study of liberal arts and science knowledge. It is an important component of higher education to shape students into better global citizens in the 21st Century. In the recent decade, the development of GE in the Asian areas, such as the mainland China, Hong Kong, and Singapore, has drawn increasing attention [1]. Taking the opportunity of the academic structure reform in 2012, the higher education institutes in Hong Kong have developed a broad GE [2]. A new common core GE Foundation Programme has been launched in The Chinese University of Hong Kong since then. It aims to develop a common intellectual ground and build sensitivity to the cultures and concerns of human existence. To cultivate the common intellectual pursuit on the enduring questions and perennial issues of human concerns, all of the 3,600 university entrants in each year are required to study common core readings, which are excerpts of selected classics and great books, and engage in reflection and expression of their ideas through intensive seminar discussions and writings. Indicated in the website, the GE Foundation Programme equips students with the essential knowledge, attitudes, and skills for independent learning [3], as the following:

- A knowledge of major ideas that shape the world today

- An intellectual inquisitiveness in addressing issues related to their life and society

- The willingness and capacity to examine new and different ideas

- The ability to engage in intensive and close reading

- The readiness to articulate their own ideas clearly and systematically in writing and oral communication.

\section{A. The Common Core Science GE Course}

The GE Foundation Programme consists of two common core course. One of the course is "In Dialogue with Humanity", which fosters reflection on good life and ideal so-

\footnotetext{
${ }^{*}$ Corresponding author: Ming $\mathrm{Li}$

†email: liming@cuhk.edu.hk
} 
ciety. This study was conducted in the other common core GE course, "In Dialogue with Nature", which focuses on the intellectual pursuit of science and nature. It explores the physical world and the world of life through reading the science classics and the writings of great philosophers and scientists. This course has five intended learning outcomes. Students who finish this course should be able to:

1. Comprehend and discuss science-related texts

2. Identify the essential characteristics of how human beings view Nature

3. Formulate informed personal views on the societal implications of scientific explorations

4. Relate the developments in natural sciences highlighted in the course to the contemporary human condition

5. Evaluate the scopes of application, achievement, and limitations of highlighted scientific methods using multiple perspectives.

Students are required to read and discuss the excerpts selected from the science classics and influential writings of scientists and other great minds [4]. Some of the classics are listed below:

- Plato's Republic

- Euclid's Elements

- Isaac Newton's Principia

- Charles Darwin's On the Origin of Species

- James Watson's DNA: The Secret of Life

- Henri Poincare's Science and Method

- Rachel Carson's Silent Spring

- Joseph Needham's The Shorter Science and Civilization in China.

This science GE course is highly appreciated by the students. Nevertheless, studying this course, especially reading the science classics and related readings, is challenging $[5,6,7]$. Various approaches and tools have been developed to support the learning and teaching of this course. For instances, reading companion Apps, supplementary online video lectures, whiteboard animations, peer-assisted study schemes, and gamification $[8,9,10,11,12]$. However, the lack of direct experience of the content of the ideas in the classics and texts might hinder the understanding and appreciation of the classics. As stressed by Jarvis that "there is no meaning in a given situation until we related our own experiences to it" [13]. Without the real-life context in which the issues and values may emerge, or theories may apply, students cannot fully appreciate the ideas, understand the problems, and face the dilemmas, and therefore remain unable to be aware of the relevance of the course to the contemporary situations. Given this, the introduction of experiential learning is essential for students' learning in the GE course.

\section{B. Experiential Learning}

Experiential learning is a broad concept which has diverse definition and meaning in different regions. European refers to group-based human-related activities; American refers to field-based placements outside educational institutes; Australia acknowledges both perspectives [14]. In general, experiential learning engages students to learn through practical experience beyond formal instruction, furthermore undergo analysis, reflection, and abstraction processes, which transform external experience into personal experience in the learning process. Kolb stressed that "learning is the process whereby knowledge is created through the transformation of experience" [15]. According to his experiential learning model, the learning process is a four-stage cycle including (i) concrete experience, (ii) reflective observation, (iii) abstract conceptualization, and (iv) active experimentation, which allow students feel, watch, think, and to do [15]. Experiential learning provides the opportunity for students to analyze the information and integrate it into the context of their learning, which is more long-lasting and meaningful than mere observations [16]. It requires students to reflect on their learning experience instead of passively engaging in applied experiences without making the connection between those experiences and technical or theoretical concepts [17].

\section{Farming as a Learning Experience in GE}

The curriculum of the GE course consists of one-third of the class time for lectures, and two-third of time for seminar discussion, plus students' endeavors of home-reading of the classics. Without the concrete experience of the content and context of the classics and the discussed issues, the learning cycle remains incomplete and discontinued, and learning becomes less effective than it could have been. In light of this, a suitable experiential learning activity is essential for better learning of the GE course. Given that the multidisciplinary and inter-disciplinary nature of this common core science GE course, the experiential learning activity with similar natures would be the most effective. In general, the activity should have several characteristics:

(i) High relevance to the broad coverage of the classics and readings of the science GE course

(ii) Coherent integration of human knowledge about nature and the application of scientific technology

(iii) Undeniable necessity to individuals and societies

(iv) Enduring concerns and perennial reflection in history

(v) Close relationship with the lives and concerns of the students

(vi) High accessibility to the students from different disci- 
plines.

Agriculture lays the foundation of all sedentary civilizations. It is a combination of human knowledge about nature, the application of science and technology, and traditional wisdom and cultures. It needs the knowledge of the physical and biological worlds and the reflection of the humanenvironment interactions, the realization of the dilemma or moral considerations of the application of scientific technology, and the philosophy of harmonious living with nature. Today, modern agriculture is facing tremendous challenges such as overpopulation, climate change, pollution, environmental inequity, and unjust social politics. Full awareness of these issues affecting agriculture is critical for GE in the 21st Century. Given all these characteristics, experiential learning in agriculture has a great potential in GE, and thus experiential learning through farming has been introduced in the common core science GE course "In Dialogue with Nature" since 2015/16.

\section{Objective}

The objective of this study is to investigate the effects of experiential learning through farming on students' learning in the university common core science GE course "In Dialogue with Nature". In particular, students' understanding of the course materials and their reflection on the extended environmental, social, and political issues were studied.

\section{METHODOLOGY}

\section{A. Course Context}

In each semester, more than 1,800 year-one and year-two undergraduate students take the common core science GE course "In Dialogue with Nature". A class of 150 students is taught by one teacher. In each class, students have to attend a 45-minute introductory lecture of the classics of the week on Friday, followed by home-reading before participating in a 1.5-hour seminar discussion in tutorial groups (six groups of 25 students each) in the next week. Students are required to submit one reflective journal and one term paper for assignments. Apart from the weekly in-class participation in the tutorial discussions, students have to join "other participation", which counts for $6 \%$ marks of the final grade. Usually, students are required to join two to three online discussion forums for "other participation". Since 2015/16, farming practicum had been introduced in one of the classes of the science GE course to open a new option of experiential learning for "other participation".

TABLE 1

DETAILS OF THE FARMING PRACTICUM IN THE THREE ACADEMIC YEARS FROM 2015/16 TO 2017/18

\begin{tabular}{llllllll}
\hline \hline Year & Semester & Cohort & Farming Period & Duration per Event & Total No. of Students & No. of Students in Sessions & Grade Weighting \\
\hline $2015 / 16$ & Fall & Year 1 & Whole semester & 2 hours & 40 & $20+20$ & $6 \%$ \\
$2016 / 17$ & Fall & Year 1 & One-time & 3 hours & 31 & $11+10+10$ & $3 \%$ \\
$2017 / 18$ & Spring & Year 2 & One-time & 3 hours & 30 & $15+15$ & $3 \%$ \\
\hline \hline
\end{tabular}

\section{B. The Farming Practicum}

The farming practicum had been done on the rooftop of the Hui Yeung Shing Building in CUHK from 2015/16 to $2017 / 18$. Students were free to register the farming practicum at the beginning of the semesters. Successful registrants were selected by lottery due to the high popularity and limited quota. The details of the farming practicum are listed in Table 1. In brief, three farming events were organized in the spring or fall semesters for the 30 to 40 participating students in the three academic years. Students were assigned to two to three sessions in groups of 10 to 20 students per session. In 2015/16, the farming practicum lasted for the whole semester by three farming events (two hours each) by organized. One-time farming events (three hours each) were organized in $2016 / 17$ and $2017 / 18$. Students who joined the farming practicum could get a maximum of $3 \%$ to $6 \%$ marks of "other participation".

In each farming event, the farm work was demonstrated by the course teacher, followed by hands-on practice by the students. Some of the farm works included building planters, blending soil, seeding, watering, weeding, pest control, making compost, applying fertilizers, pruning, and harvesting (Figure 1). Briefing and debriefing discussions were guided at the beginning and the end of each farming event. The guided discussions introduced various concepts in farming and bridged the gap between the farm work and the classics in the GE course. Students read and discussed the selected excerpts from the classics together before or after the hands-on practice in each farming session. Some excerpts are given below as examples:

"Let it be borne in mind how infinitely complex and closefitting are the mutual relations of all organic beings to each other and to their physical conditions of life." from Charles Darwin's On the Origin of Species (1859);

"The earth's vegetation is part of a web of life in which there are intimate and essential relations between plants and the 
Earth, between plants and other plants, between plants and animals. But sometimes we have no choice but to disturb these relationships, but we should do it thoughtfully, with full awareness that what we do may have consequences remote in time and place." From Rachel Caron's Silent Spring (1962);

"Schrodinger argued that life could be thought of in terms of storing and passing on biological information." and "Life was just a matter of physics and chemistry, albeit exquisitely organized physics and chemistry." from James Watson's DNA: The Secret of Life (2003).

Although experiential learning can exist without teachers, guided discussion modulated by teachers is important for the motivation of student learning. Teachers are not information providers but motivators or coaches, who create appropriate learning conditions for the students, such as refocusing students' learning priorities, motivating when necessary, breaking down the resistance to learn, prompting reflective questions, thoughts, and actions $[18,19]$. The guided discussion aimed to consolidate learning and fos- ter reflection. It covered the topics directly associated with the classics and philosophical questions which are seemingly distant from the farm work. For instance, students traced the roots from the aerial part of "one" grass when doing the weeding practice. A closer look into the horizontal rhizome and root systems of the grass led to the discovery of the fact that these aerial parts of the many "individual grass" were interconnected, which inferred that all this "individual grass" was actually "one life". Students were asked to cut these horizontal connections, and each of the separated grass could become an individual life, which inferred that there were many lives then. The guided discussion of the weeding farm work inspired and challenged the students what it means by "a life". Students were asked to rethink their views on James Watson's quote (shown above) whether life is just a matter of physics and chemistry. By witnessing the vegetative reproduction of grass and other plants, students gained a better understanding of Watson's physicalism worldview and the reductionist nature of science.
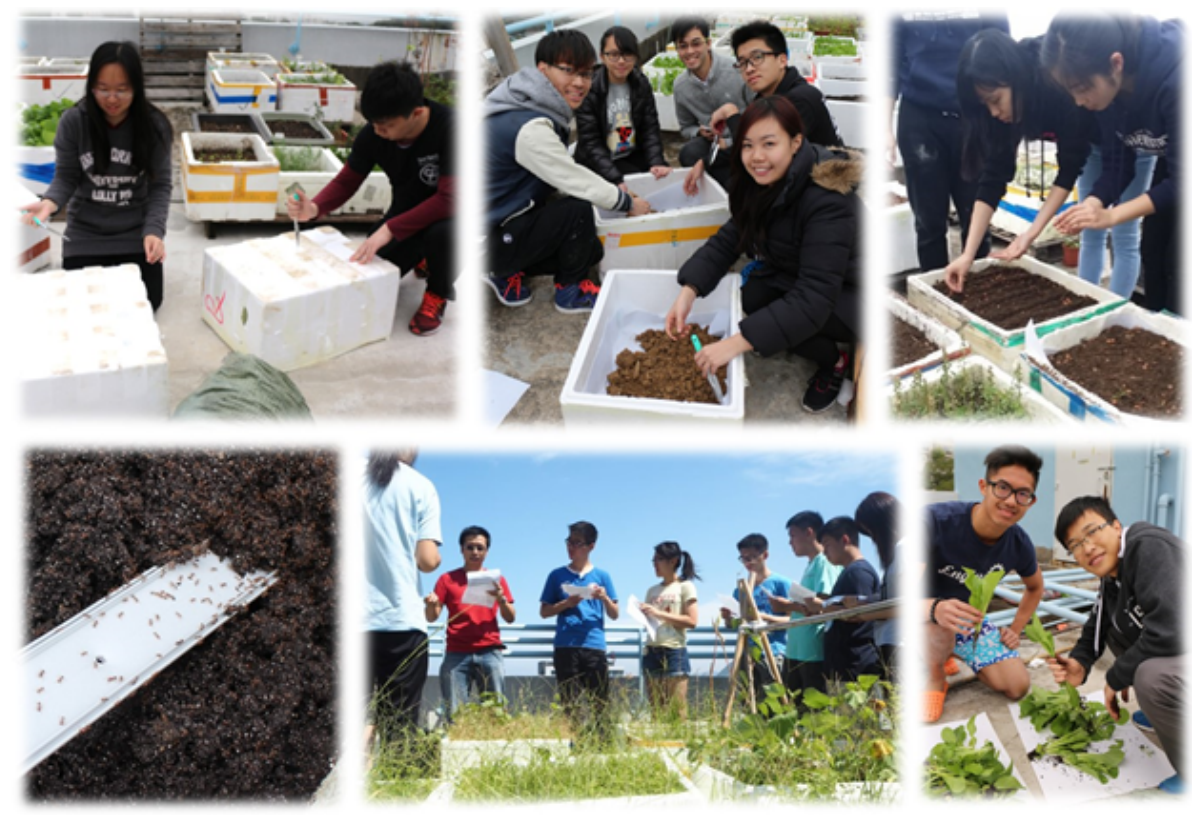

Fig. 1. The farming practicum showing the upcycle of wasted foam boxes (upper left), blending soils (upper middle), seeding (upper right), a swam of ant pest (lower left), guided discussion (lower middle), and harvesting (lower right)

The guided discussion was closely related to the classics, the nature of science, environmental issues, social aspects, moral dilemma, ways of living, and other philosophical issues. Some of the issues associated with agriculture and food growing include sustainable agriculture, organic and conventional farming, seasonal vegetables, use of chemicals, pest control, climate influence, recycling and upcycling, consumption styles and habits, social community building, farmland policy, food justice, and agricultural ethics.

\section{Data Analysis}

Quantitative feedbacks were collected by conducting surveys at the end of the farming practicum using a six-point Likert scale from " 1 " representing "strongly disagreed" to 
"6" representing "strongly agreed". The mean score was compared with the mid-score 3.5 of the Likert scale using the one-sample $t$-test. A $p$-value of less than 0.05 is considered statistically significant. Qualitative feedbacks were also collected by these surveys, and students' reflections were analyzed from their written assignments.

\section{RESULTS}

\section{A. The Popularity of the Farming Discussion}

The new attempt of introducing farming practicum as an option for "other participation" in 2015/16 gained high popularity among the students. There were 101 students (73.2\%) out of the 138 students in 2015/16 who tried to register the farming practicum. A survey was conducted to reveal their reasons for choice (Table 2). In general, they were interested in the new, hands-on, outdoors, active, and interactive learning experience. These students found that online discussion forums were boring, ordinary, and repetitive of the discussion in class. Some of them worried that they were unable to express themselves properly by writing, and did not want to do reflection in front of computers. On the other hand, 37 students (26.8\%) chose to do the online discussion forums for "other participation". They were willing to write their ideas indoor and found the online discussion forums were more flexible, convenient, and comfortable. They did not choose farming practicum because of the inconvenience and unfit schedule.

TABLE 2

MAIN REASONS FOR CHOICE OF FARMING PRACTICUM AND ONLINE DISCUSSION FORUM

\begin{tabular}{|c|c|c|}
\hline & Farming Practicum $^{\#}$ & Online Discussion Forums ${ }^{\#}$ \\
\hline Reasons for Joining & $\begin{array}{l}\text { - Seems interesting } \\
\text { - Want to try something new } \\
\text { - Can have hands-on experience } \\
\text { - Want to learn outdoors } \\
\text { - More active and interactive learning } \\
\text { - Should be a memorable experience }\end{array}$ & $\begin{array}{l}\text { - Like to express the ideas in writing } \\
\text { - More flexible, convenient and comfortable } \\
\text { - Want to stay indoors }\end{array}$ \\
\hline Reasons for Not Joining & $\begin{array}{l}\text { - Time is not suitable } \\
\text { - Less convenient } \\
\text { - Planting is hard } \\
\text { - Not interested in planting } \\
\text { - Not good at expressing thyself by writing }\end{array}$ & $\begin{array}{l}\text { - Seems boring } \\
\text { - Ordinary and similar to many other assignments } \\
\text { - Can discuss in class } \\
\text { - Do not want to reflect in front of the computer }\end{array}$ \\
\hline
\end{tabular}

\#101 students (73.2\%) chose farming practicum; 37 students (26.8\%) chose online discussion forums

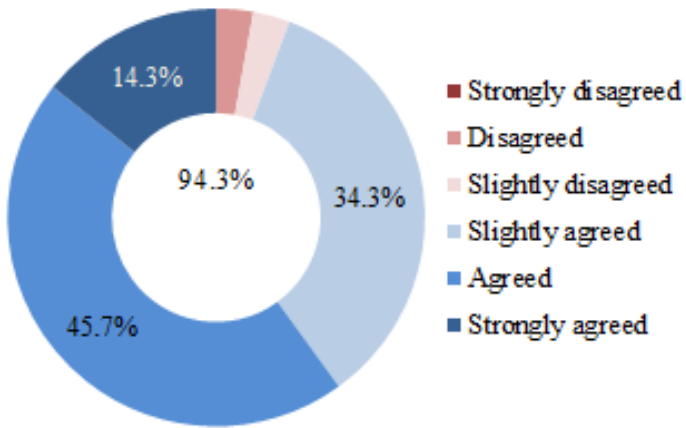

Fig. 2. Helpfulness of farming practicum in better understanding of the course materials in $2015 / 16$

\section{B. Understanding of the Course Materials}

The primary goal of the introduction of experiential learning through farming was to help students' understanding of the course materials. Our survey showed that $94.3 \%$ of the students agreed in different degrees (34.3\% slightly agreed, $45.7 \%$ agreed, and $14.3 \%$ strongly agreed) that the farm- ing practicum was helpful for better understanding of the course materials (Figure 2). The mean score in the sixpoint Likert scale is 4.7 ( $p<0.05$ in one-sample $t$-test). The qualitative feedback also supported that the farming practicum helped students understand and reflect on the classics. Some of the students' comments on the helpful- 
ness of the farming practicum in the understanding of the classics are quoted below (quotes A1 to A7).

On Rachel Carson's Silent Spring:

A1: It helped me to rethink the role of human beings, the relationship between human and nature, in particular, those issues related to the environment."

A2: "It enlightened me to have a better appreciation of the author's arguments on the abuse of herbicides."

A3: "It demonstrated using real examples that the use of [artificial] chemicals is not the best solution to control the pest."

A4: "I realized that it is not a must to apply artificial chemicals to grow the crops."

On Charles Darwin's On the Origin of Species:

A5: "I had a chance to rethink the idea of inheritance of the characteristics of the crops from the comment ancestors."

On James Watson's DNA: The Secret of Life:

A6: "It deepened my reflection on the idea of "life". From the environmental factors and their interaction with the genes in the seeds, I can better appreciate what it means by 'life is just a matter of physics and chemistry."'

On Joseph Needham's The Shorter Science and Civilization in China:

A7: "I understand better the natural worldview of yin-yang and the way of living with nature harmoniously."

\section{Understanding of Extended Issues in $G E$}

The guided discussion in farming practicum did not limit to the context and content of the classics. Extended questions associated with the environmental, social, and political issues, and the science and techniques used in agriculture were naturally integrated into the guided discussion. For examples, environmental pollution caused by the overuse of pesticides and fertilizers, the impact of climate change on farming, community support of farmer markets, the tension between urban development and conservation of farmlands and villages, the sustainability of agriculture, and the knowledge on seasonal farming. Our study showed that all students agreed in different degrees (25.7\% slightly agreed, $45.7 \%$ agreed, and $28.6 \%$ strongly agreed) that farming practicum was helpful for their understanding of environmental issues (Figure 3). The mean score in the six-point Likert scale is 5.0 ( $p<0.05$ in one-sample $t$-test).
There were $85.8 \%$ and $97.2 \%$ students agreed the farming practicum is helping in reflecting the social and political issues (34.3\% slightly agreed, $42.9 \%$ agreed, and $8.6 \%$ strongly agreed) and obtaining knowledge and techniques in farming (14.3\% slightly agreed, $48.6 \%$ agreed, and $34.3 \%$ strongly agreed), respectively (Figure 3 ). The mean scores are 4.3 and 5.1 (both $p<0.05$ in one-sample $t$-test), respectively. The qualitative feedbacks aligned with the quantitative data that the farming practicum helped students to reflect on the environmental, social, and political issues, and obtain the knowledge and techniques in farming. Some feedbacks are quoted below (quotes B1 to B9).

On environmental issues:

B1: "The impact of climate change and the weather have made farming difficult."

B2: "The farming experience has fostered the reflection of my living style, especially those related to different forms of agriculture, food consumption, and environmental conservation."

B3: "I did not think about the carbon footprint in the food production and transportation processes when choosing vegetables. I will try to buy more local foods now."

On social and political issues:

B4: "I am impressed that our food consumption can make an impact on the living of the people on the other side of the Earth."

B5: "I have learned more about the rationale and policy in land use in Hong Kong."

B6: "I am more conscious about the Government's environmental policies. The Government has focused too much on urban development and housing, and has sacrificed too many farmland and countryside."

On knowledge and techniques in farming.

B7: "Now I know doing organic farming is not easy at all. This farming experience makes me realize that everyone can support organic farming from a different dimension, such as buying more organic food, and learning organic farming."

B8: "I am impressed by the recycling and upcycling of wasted materials in the rooftop farm. The green and food wastes for making compost are worth exploring."

B9: "The structure of grass is amazing. I never know it even I see grass every day." 


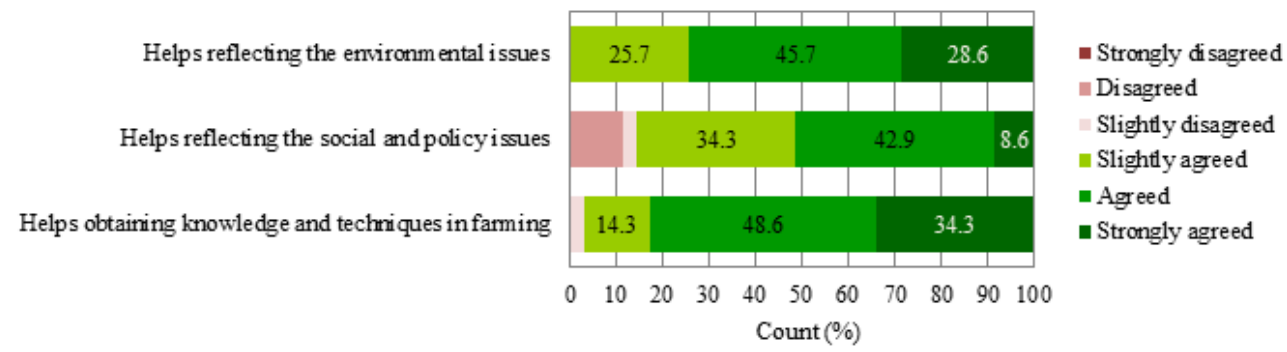

Fig. 3. Helpfulness of farming practicum in better understanding of extended issues in GE in 2015/16

\section{Overall Satisfaction}

Our survey data showed that all students who joined the farming discussions were satisfied with the farming practicum in general (Figure 4). In an average of the three years from $2015 / 16$ to $2017 / 18,11.2 \%$ students gave score $4,52.2 \%$ gave score 5 , and $34.8 \%$ gave the highest score 6 in the six-point Likert scale. The mean score ranged from 5.1 to 5.3 ( $p<0.05$ in one-sample $t$-test) for the three years. These scores indicated that the farming practicum had been well-received by the students. Some of their feedbacks in the surveys are quoted below (quotes $\mathrm{C} 1$ to $\mathrm{C} 6$ ).

C1: "The ideas discussed in the farming practicum match with In Dialogue with Nature. It farming practice is more engaging than doing online discussion forums."

C2: "I enjoy the hands-on experience to 'feel' the lives in nature, not just get the knowledge from books."

C3: "It feels great when you actually touch the soil and plants. It is far better than just listening and talking in lectures."

C4: "I really appreciate that we can learn rooftop farming and eat the vegetables grown by ourselves together."

C5: "The lesson is innovative, practical and fun. It is a unique and memorable experience for me."

C6: "The farming activity is enjoyable. It helps me to ease the pressure of my study."

\section{DISCUSSION AND CONCLUSION}

The common core science GE course "In Dialogue with Nature" inspires students through the reading of the classics by lectures, discussion seminar, and reflective writings. Using the cone of experience as a visual analogy, Dale suggested that direct, purposeful experience lays the foundation of the progression of the learning experience. The wealth of meaningful information and ideas are built through the unabridged experiences of life [20]. Without experiencing the content and context of the texts in real-life situations often hinders students' appreciation of the texts and reflection of the issues. Given this, experiential learning through farming had been introduced in the science GE course, and this study investigated the effects of its implementation.

\section{A. Helpfulness in Learning the Science GE Course}

Most students (94.3\%) reported that the farming practicum helped them to understand the texts better (Figure 2; quotes A2, A5, and A7, for instance), and the examples and experience in the real-life situations fostered their understanding and reflection of the course contents (quotes A3 and A6). Quite often, students find that some concepts in the classics are too difficult to grasp. For instance, the reductive approach of understanding life in modern science, illustrated as just a matter of physics and chemistry, seems strange and is unacceptable for many students. Students might not have to agree on this approach of viewing life, but they should understand what this approach really means before making informed reflection. Understanding the physical processes and chemical reactions in seed germination in response to the environmental factors helped students to understand this reductionist approach suggested in James Watson's writings (quote A6). Another example is the holistic worldview of yin-yang in Chinese natural philosophy. It might look absurd when one does not know the patterns of the natural world and the influence of culture on the worldview. The farming practicum let the students experience the farming routines, and the considerations and adaptations of the farmers in response to the change of nature. Students' feedback showed that the practicum fostered their understanding of the concepts of the two complementary forces, yin and yang, and appreciation of the living style of the Chinese tradition (quote A7). These feedbacks implied that the farming practicum is able to turn abstract ideas in the course into real experiences. Concrete, direct, and firsthand experience lays the foundation of learning [20]. Ortega suggested that the direct experience builds a concrete experience which reinforces the lecture-acquired concepts [21]. Although the sentences and concepts of some course materials, for example, Rachel Carson's Silent Spring, are easy to read, the lack of experience in 
real-life context and situations may hinder students' understanding and reflection of the ideas, such as the use of pesticides and alternatives. Students who experienced farming might understand that nature is far from Utopia. Sometimes it wreaks havoc on crops without notice. A student shared her experience in an interview that the farming experience displayed a real-life situation "During one session, we watched a swarm of ants pour out from their nest in a planter box. It was a cold day and their sheer number gave us a shock. During the session, we discussed Rachel Car- son's book Silent Spring, which had sparked widespread debate about the use of pesticides. This experience helped put us in the shoes of farmers facing a similar dilemma, and enabled us to understand where they're coming from in the controversy concerning pesticides" [22]. Feedbacks from other students agreed that the real-life experience and situation helped their understanding of the ideas in Carson's texts (quotes A2 and A3). The meaning of the text is better revealed by experiencing it than listening or discussion without real-life experience.

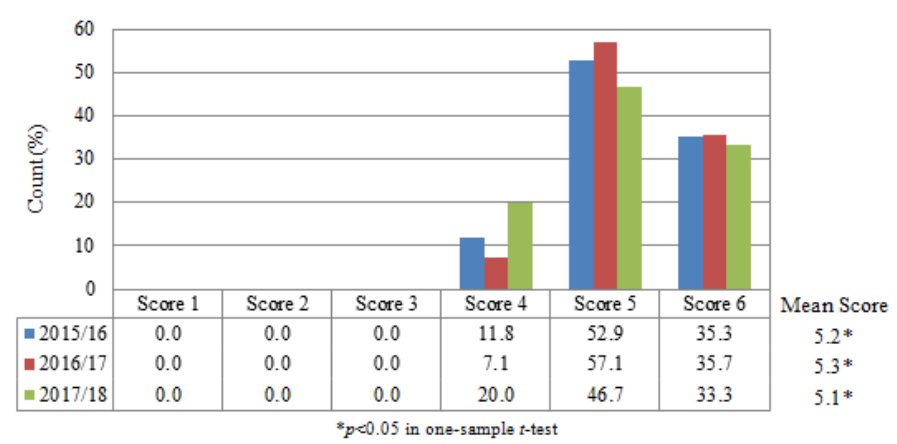

Fig. 4. General satisfaction of the farming practicum from 2015/16 to $2017 / 18$

Revealed by the surveys in this study, students also acknowledged that the farming practicum helped them to understand the extended issues related to the environmental issues (100\%), and social and political issues (85.8\%) (Figure 3; quotes B1, B4, B5, and B8). The farming practicum helped them to be aware of the current situations and integrate the objective experience into their personal learnings. For instances, the reflection of their consumption styles in response to the environmental issues (quotes B2 and B3), and their choice of actions to support organic farming (quote B7). In general, students are satisfied with the farming practicum for the experiential learning of the science GE course in the three consecutive years from 2015/16 to $2017 / 18$ (Figure 4).

\section{B. Student Engagement and Motivation}

One of the challenges for experiential learning is how to engage students. The experiential quality depends on the degree of students' involvement in the practical activities and the relevance of the subject matters [19], while the unwillingness for participating in the experiential learning is one of the main challenges of the practical courses in higher education [23]. The engagement and motivation for joining the farming practicum are worth exploring. We surveyed the intention of choosing farming practicum or online discussion forums for "other participation" in 2015/16. About three-forth $(73.2 \%)$ of the students wish to join farming practicum. The reasons given by these students (Table 2) and the feedbacks of the students who actually participated in the farming practicum (quotes $\mathrm{C} 1$ to $\mathrm{C} 3$ ) showed that hands-on practices were relevant to the GE course, more engaging than attending lectures, reading the texts, and discussion through online platform. Some feedbacks indicated that the direct experience, relaxing learning environment, and enjoyable moments are the attractions (quotes $\mathrm{C} 4$ to C7). Despite the popularity and helpfulness of the farming practicum, it is worth noticing that about one-fourth of students did not want to join the farming practicum for different reasons (Table 2). These findings supported that the students' learning styles and needs are diverse. It is understood that the students in the common core course have very diverse academic backgrounds, learning styles, and needs. Providing online discussion forums as the only option for "other participation" may not be able to cater to students' needs. Similarly, it is better to keep farming practicum as an option instead of compulsory activity.

\section{Limitations and Challenges}

The effects of introducing experiential learning through farming in the GE course was studied based on students' subjective feedbacks, quantitatively and qualitatively, collected from surveys. The feedbacks agreed that farming practicum is helpful in studying the GE course. One should note that these feedbacks were collected from students who 
wished to join and successfully participated in the farming practicum. These students might be more active, motivated, and engaged in experiential learning, and this might cause selection bias in this study. Objective measurement of the effectiveness of the farming practicum in this classicsreading and seminar-based GE course would be insightful but very challenging. One limitation of this study is that the effectiveness of farming practicum, in terms of personal reflection on the enduring questions and extended issues, could not be objectively quantified and statistically compared.

For the implementation of farming practicum, Nooghabi studied some challenges of experiential learning of practical courses in agriculture [23]. Some of them were also faced in this study. For examples, finding a suitable farming place with sufficient space and convenient location was not easy. Our farming practicum was done on the rooftop of a teaching building. The loading capacity, water drainage, accessibility, and safety should be carefully managed. The space of the farmland and manpower had limited the number of participants, farming events, and sessions. Agricultural knowledge and farming techniques are pre-requisites. Although briefings and demonstrations were given and $97.2 \%$ of the students agreed that they had gained knowledge and techniques in farming (Figure 3), daily maintenance of the farmland and taking care of the crops were still challenging, especially when unpredictable circumstances, such as pest invasion, were encountered. Unstable weather and the influence of typhoons also affected the outdoor farming activities, the yield, and in turn, the learning experience of the students. These challenges, however, might not be bad entirely. With a properly guided discussion, these challenges could be turned into valuable opportunities for students to feel the difficulty and taste the bitterness of farming in reallife situations.

Apart from the abovementioned inputs for the implementation of farming practicum, there are some pedagogy concerns for designing experiential learning activity in general. For instances, a successful experiential learning activity requires the integration and implementation of well-selected educational, experiential learning, and youth development theories [23]. The farming practicum, in accordance with the pedagogical theories, should be systematically reviewed and carefully designed. Besides, the ambiguity in learning outcomes and students' achievements could be another concern. When the learning experience is a central element of a course curriculum, the learning outcomes and students' achievements would be more difficult to articulate and less controlled [24]. The farming practicum in this study was a part of the course participation but it weighted relatively small (3\% to $6 \%$ ) in the grade calculation. Instead of setting detailed learning outcomes, a grading rubric with carefully developed assessment criteria and standards could be used as a reference for students to understand the expectations of the farming practicum.

\section{Conclusion and Prospect}

This study aims at investigating the effects of experiential learning through farming on students' learning in the university common core science GE course "In Dialogue with Nature” in Hong Kong. Students' feedbacks showed that the farming practicum helped the students to better understand the course materials and the extended issues, including environmental, social, and political issues. Echoing with the quote, "it is better to travel ten thousand miles than to read ten thousand books", the farming practicum did not only enrich students' learning experience, "it also served the important functions of linking the knowledge from books to the real world through the illustration of real-life examples, and enhancing the understanding of the meaning of the course materials by illustrating abstract concepts with contextual situations." This study provides insightful findings to support the introduction of experiential learning through farming to help learning and teaching in university science GE. GE is far more than "gaining common knowledge from various major disciplines" as the words "General Education" may have been commonly perceived. The essence of GE is the development of the ability to connect knowledge from different disciplines, to find similarity behind seeming discrepancies, to identify discrepancy from seeming similarities, and to integrate the knowledge with real-life situations. Agriculture is the integration of the knowledge on nature (e.g., science and other worldviews), human needs (e.g., food, humanity, and ethics) and cultures (e.g., arts and traditions). Given the diverse aspects and interdisciplinary nature of agriculture, experiential learning through farming could be extended to other GE courses, such as "In Dialogue with Humanity". Through the farming practicum, students can better understand the course materials and appreciate the ideas, feel the struggles and face the dilemma in real-life situations, experience the impact of the global challenges, taste the urgency for sustainable development, and become better global citizens.

\section{ACKNOWLEDGMENT}

Gratitude is given to the Office of University General Education for the support of the implementation of experiential learning through farming in these years. 


\section{REFERENCES}

[1] J. C. Hammond, "A new core texts course in Singapore," Journal of General and Literal Education, vol. 9, no. 5, pp. 43-83, 2016.

[2] J. Gaff, "General education reform in Hong Kong: Leadership for success," Journal of General and Literal Education, vol. 8, pp. 1-27, 2014.

[3] Office of University General Education, "General education foundation programme," 2013. [Online]. Available: https://bit.ly/35WGFpG

[4] C. C. Chan, W. M. Szeto, and W. H. Wong, Textbook for General Education Foundation Programme. Beijing, China: Office of University General Education Press, 2016.

[5] K. Kiang, A. Ng, and D. Cheung, "Teaching science to non-science students with science classics," American Journal of Educational Research, vol. 3, no. 10, pp. 1291-1297, 2015.

[6] W. H. S. Hoi, W. H. Wong, and K. M. Pang, "Confronting students' science anxiety through 'in dialogue with nature," in The European Conference on Education, California, CA, 2017.

[7] K. C. Lau, M. Li, and L. Liao, 'Assessment of students' views of nature of science in the context of the discovery of DNA structure," in Proceedings of Multidiscplinary Academic Conference, Czech, Prague, 2018.

[8] D. H. C. Cheung, S. W. H. Hoi, A. K. L. Ng, K. M. Pang, and W. H. Wong, "Dianable: A reading-companion mobile app for science core-text teaching at the Chinese university of Hong Kong," in Teaching and Learning with Technology, F. Wilton and V. W. Li, Eds. Jurong East, Singapore: World Scientific, 2017.

[9] K. M. Kiang, H.-Y. Chan, A. K.-L. Ng, and D. H.-C. Cheung, "Effectiveness of micro-modules in a science classics course," American Journal of Educational Research, vol. 4, no. 13, pp. 917-926, 2016.

[10] M. Li, C. W. Lai, and W. M. Szeto, "Whiteboard animations for flipped classrooms in a common core science general education course," in 5th International Conference on Higher Education Advances, Valencia, Spain, 2019. doi: https: //doi.org/10.4995/HEAD19.2019.9250

[11] A. K. Ng, D. H. Cheung, and K. M. Kiang, "E-learning implementation in a compulsory science general education course," in Proceedings of Multidisciplinary Academic Conference, Prague, Czech Republic, 2016.

[12] W. M. Szeto, K. T. Wong, M. Li, J. Wu, L. M. Yip, K. Y. Lai, C. C. Yu, K. L. Ng, and M. Y. Leung, "What we have passed through: The development of PASS in the general education foundation programme from 2010 to 2018," 2018. [Online]. Available: https://bit.ly/2Rtg3ZN

[13] P. Jarvis, "Meaningful and meaningless experience: Towards an analysis of learning from life," Adult Education Quarterly, vol. 37, no. 3, pp. 164-172, 1987. doi: https://doi.org/10.1177/0001848187037003004

[14] D. Boud, "Some competing traditions in experiential learning," in Making Sense of Experiential Learning: Diversity in Theory and Practice. Buckingham, UK: Open University Press, 1989.

[15] D. A. Kolb, Experience as the Source of Learning and Development. Upper Sadle River, NJ: Prentice Hall, 1984.

[16] M. Garvin and R. Ramsier, "Experiential learning at the university level: A US case study," Education Training, vol. 45, no. 5, pp. 280-285, 2003. doi: https://doi.org/10.1108/00400910310484349

[17] K. M. Vespia, G. Wilson-Doenges, R. C. Martin, and D. M. Radosevich, "Experiential learning," in Evidence-Based Teaching for Higher Education, B. M. Schwartz and R. A. R. Gurung, Eds. New York, NY: American Psychological Association, 2012.

[18] A. Thomas, Coaching for Staff Development. Leicester, UK: British Psychological Society, 1995.

[19] J. Fowler, "Experiential learning and its facilitation," Nurse Education Today, vol. 28, no. 4, pp. 427-433, 2008. doi: https://doi.org/10.1016/j.nedt.2007.07.007

[20] E. Dale, "A truncated section of the cone of experience," Theory into Practice, vol. 9, no. 2, pp. 96-100, 1970. doi: https: //doi.org/10.1080/00405847009542260

[21] K. Ortega, W. Murayama, L. Holmes, S. Taylor, and E. DePeters, “Experiential learning exercises to enhance learning in a university nutrition course," The Professional Animal Scientist, vol. 27, no. 6, pp. 591-598, 2011. doi: https://doi.org/ 10.15232/S1080-7446(15)30544-1

[22] Campus Planning and Sustainability Office, "An earthy exercise: Dialogue with nature via rooftop farming," 2016. [Online]. Available: https://bit.ly/2Rjij5I

[23] S. N. Nooghabi, H. Iravani, and H. S. Fami, “A study on present challenges on experiential learning of university students (University of Tehran, the colleges of agriculture and natural resources, Iran)," Procedia-Social and Behavioral Sciences, 
vol. 15, pp. 3522-3530, 2011. doi: https://doi.org/10.1016/j.sbspro.2011.04.329

[24] R. E. Hansen, "The role of experience in learning: Giving meaning and authenticity to the learning process in schools," Journal of Technology Education, vol. 11, no. 2, pp. 23-32, 2000. doi: https://doi.org/10.21061/jte.v11i2.a.2 